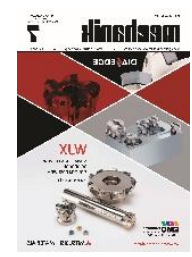

How to cite this article:

Authors: Krzysztof Zieliński, Andrzej Piotrowski

Title of article: „Analysis of construction of autonomous rotary table”

Mechanik, No. 7 (2019)

DOI: https://doi.org/10.17814/mechanik.2019.7.56

\title{
Analysis of construction of autonomous rotary table
}

\author{
KRZYSZTOF ZIELIŃSKI \\ ANDRZEJ PIOTROWSKI*
}

Inż. Krzysztof Zieliński, krzysiek.ziel@poczta.pl

Dr inż. Andrzej Piotrowski, apiotr@itm.pcz.pl, https://orcid.org/0000-0001-6382-200X - Politechnika Częstochowska, Częstochowa, Polska

The article presents an analysis of the construction of an autonomous rotary table dedicated to coordinate measuring machines. The axis of the table rotation is the fourth, controlled axis extending the capabilities of the classical three-axes measuring machine with the possibility of measuring objects with repetitive contours on the circumference: gears, hobs, etc. The analysis was performed using the CAD/CAE Autodesk Inventor Professional 2018 program.

KEYWORDS: rotary table, coordinate measuring technique, CAD/CAE systems

\section{Introduction}

Coordinate measuring technology has revolutionized industrial metrology - it has enabled complex measurements and shape analyses to be carried out in a very short time, in one clamping of the measured object, and has replaced classic, time-consuming measuring methods. The measurements are carried out in an automatic cycle, which ensures that the impact of human error is minimized.

The field of application of classic coordinate measuring machines that have three axes is limited. By equipping these machines with a rotary measuring table, i.e. the fourth indexed axis, it is easier and faster to measure objects having a rotational axis, such as gears, bearing rings or turbines, especially worm cutters (their measurement without the use of a rotary measuring table is impossible). Rotary measuring tables allow the use of stylus with a simpler configuration and allow for the measurement of most elements of the object being measured by means of a single mandrel working in the $Z$ axis. Such tables ensure the optimal positioning of the measured part in relation to the stylus tip and thus shorten passages or eliminate them completely [1-3].

\section{Project assumptions}

Manufacturers of CMMs offer rotary tables, but they are usually expensive and can only be used on selected machines.

The main goal of the authors was to analyze the design of a universal, i.e. virtually autonomous rotary table, which can be used in any measuring machine or measuring device. The table should have: direct drive system, rotary incremental measuring system, aerostatic bearing and - due to the limitations of the measuring range the lowest casing and low weight. Its suitable temperature range is $20 \div 21^{\circ} \mathrm{C}$. The rotation control system and measuring system must be possible to implement in various programs controlling the work of coordinate measuring machines, and additionally they should be able to work autonomously.

\section{Universal rotary table design}

Structural and strength analysis was carried out in Autodesk Inventor Professional 2018. It is a typical CAD program used to create individual parts as 3D models, and then to assemble them into one assembly with the ability to determine the kinematic dependencies of the cooperating parts and carry out strength analysis of the designed structure by means of FEM method. After the compatibility analysis and kinematic and strength analyses of the cooperating elements, it is possible to automatically generate the assembly and assembly drawings and to make constructional changes on an ongoing basis without the need to build a real model. Autodesk Inventor Professional 2018 works on any operating system from the Microsoft Windows family [4].

Basic element of the design of the rotary measuring table (fig. 1) is the disc, on which the measured element rests. It has the ability to turn due to bearings. The measuring systems use super-precision rolling bearings or, if possible, aerostatic bearings. Unlike rolling bearing, the aerostatic bearing does not wear, and also has the ability to self-clean, so it ensures long and precise work. 
Innovative air bearings were used in the table construction (fig. 2) [5]. Air bearing is based on the phenomenon of airbag formation between the moving element of an object and bearing assembly, which is caused by a stream of compressed air flowing. In classic bearings, air escapes from a single hole, usually located in the center. This causes an uneven distribution of air between the bearing and surface, on which it moves. Therefore, after conducting the analysis, it was decided to use bearings equipped with a porous contact surface, through which air passes evenly. In this way, the highest bearing accuracy and high system load capacity were achieved [5].

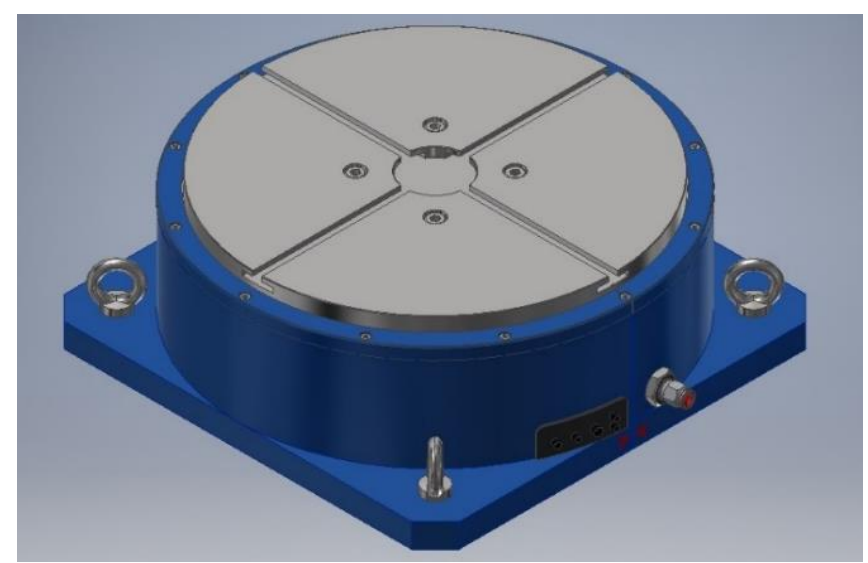

Fig. 1. 3D model of the rotary measuring table

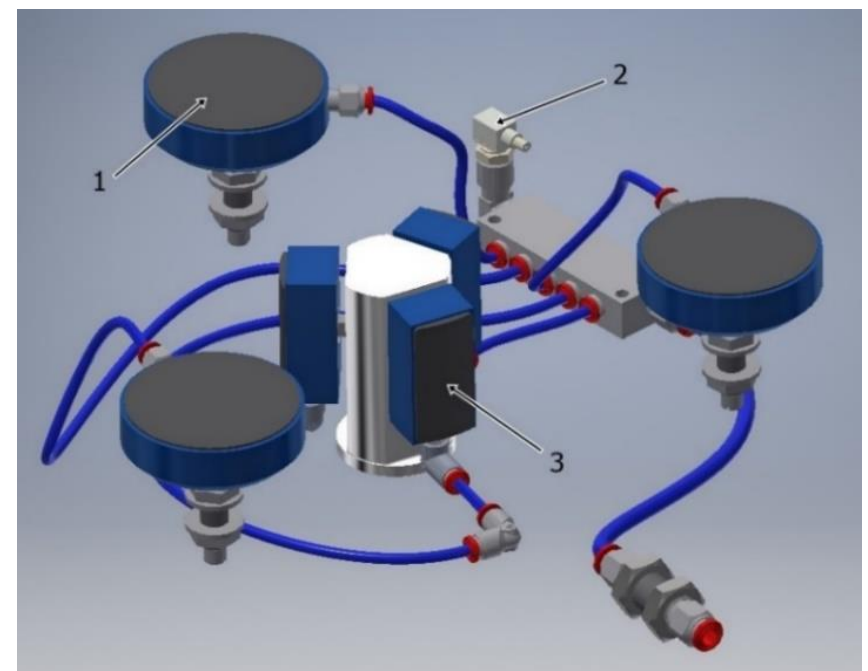

Fig. 2. 3D model of the bearing arrangement with pneumatic system connection: 1 - axial bearing, 2 air pressure sensor, 3 - radial bearing

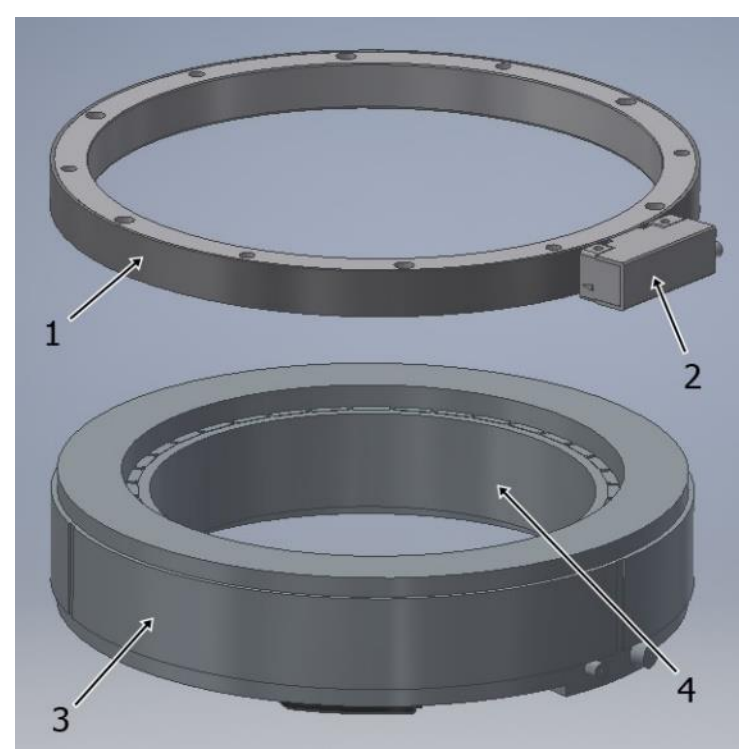

Fig. 3. 3D model of the drive and measuring system: 1 - measuring ring, 2 - reading head, 3 - electric motor stator, 4 - electric motor rotor 


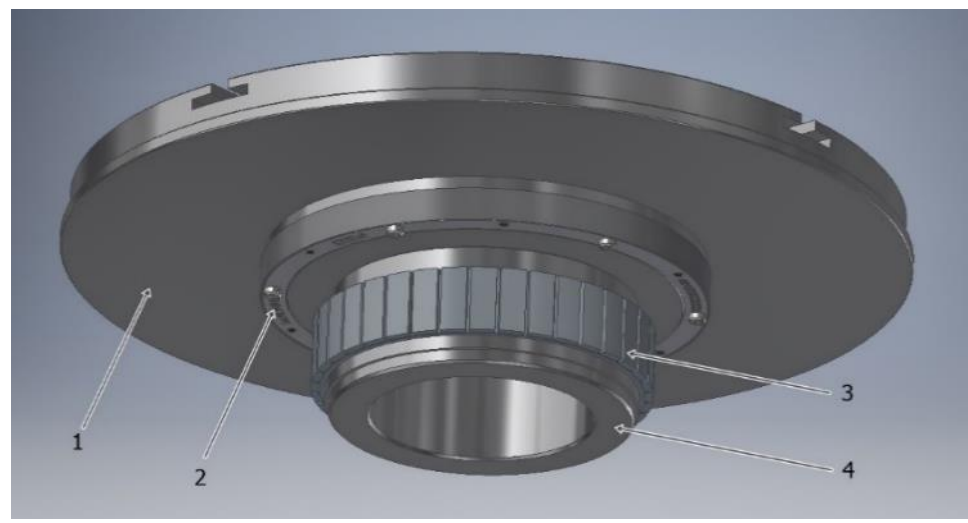

Fig. 4. Assembly of 3D models with the table disk: 1 - table disk, 2 - measuring ring, 3 - electric motor rotor, 4 - middle sleeve

The table is equipped with three flat air bearings with a diameter of $65 \mathrm{~mm}$ lifting the measuring table disk, and three radial air bearings with a convex profile and dimensions $25 \times 50 \mathrm{~mm}$, that keep the moving elements in the appropriate axial position (fig. 2). To protect bearings and surfaces that work with them, a compact air pressure sensor was selected to monitor the operating pressure range. The bearings were connected to the pneumatic system by means of compact plug-in connectors and flexible pneumatic hoses (fig. 2).

The measuring table is equipped with an incremental magnetic ring encoder with a Renishaw LM13 reading head, measuring the rotation angle of the table (fig. 3). Measuring system is attached directly to the measuring table disk and provides a reading accuracy of $0.006 \mathrm{~mm}$ with a $0.6 \mathrm{~mm}$ gap between measuring ring and reading head. The system has very high measuring resolution of $0.000244 \mathrm{~mm}$, as well as dirt resistance and reliability - due to non-contact operation [6].

In order to eliminate the clearances characteristic of classic gears in the tested construction, a direct drive transmission system was used (fig. 3) [7]. The torque motor used is characterized by high positioning precision of several arc second (positioning accuracy depends on the accuracy of the measuring system used), and high rigidity. It requires no maintenance and has a compact design, which allows to reduce the total height of the table. The motor is equipped with a Hall sensor (located on the stator), which is applied to determine the position of the rotor to increase positioning precision. The engine torque is $15.7 \mathrm{Nm}$ (continuous torque) and is available from the lowest rotational speed values, which ensures the right angular position of moving units of the designed table $[7,8]$.

The designed system (fig. 4) has no mechanical connections with other parts of the measuring table, which determines the long and trouble-free operation of the device. The table wheel, which is directly aerostatically mounted, has a load capacity of approximately $188 \mathrm{~kg}$, and the measuring system attached to the wheel ensures the highest measuring accuracy (see table). Direct drive guarantees positioning accuracy and repeatability.

TABLE. Technical parameters of the rotary table

\begin{tabular}{|l|c|}
\hline Weight & $\sim 26 \mathrm{~kg}$ \\
\hline Load capacity & $\sim 188 \mathrm{~kg}$ \\
\hline Heigh & $120 \mathrm{~mm}$ \\
\hline Measuring disc diameter & $\varnothing 300 \mathrm{~mm}$ \\
\hline Centering hole diameter & $\emptyset 50 \mathrm{~mm}$ \\
\hline Bearing method & Aeristatic bearing \\
\hline Measuring system & Direct, incremental \\
\hline Drive transmission & Direct \\
\hline Maximum / continous torque & $35.4 / 15.7 \mathrm{Nm}$ \\
\hline
\end{tabular}

\section{Construction analysis}

FEM analysis was carried out on the 3D model of the rotary measuring table with imposed kinematic relationships and defined materials: AISI 440C steel (table) and aluminum PA 45 (body) (fig. 5). It was assumed that the structure load, equivalent to the point pressure distributed on the surface of $4535 \mathrm{~mm}^{2}(\varnothing 100 \mathrm{~mm})$ and 640 $\mathrm{mm}^{2}(\varnothing 60 \mathrm{~mm}$ ) (central hole, chamfers and T-slots included) and equal to the maximum pressure exerted by the measured detail (188 $\mathrm{kg}$ ), will be applied in the table's axis of rotation and $100 \mathrm{~mm}$ from the axis of rotation, i.e. in the most sensitive place (T-slot, no support at the place of maximum load) to simulate uneven table load 
(figs. 6 and 7). The model was simplified and the key load-bearing elements of the measuring table were analyzed (without taking into account parts that did not affect the load capacity), which facilitated the interpretation of results.

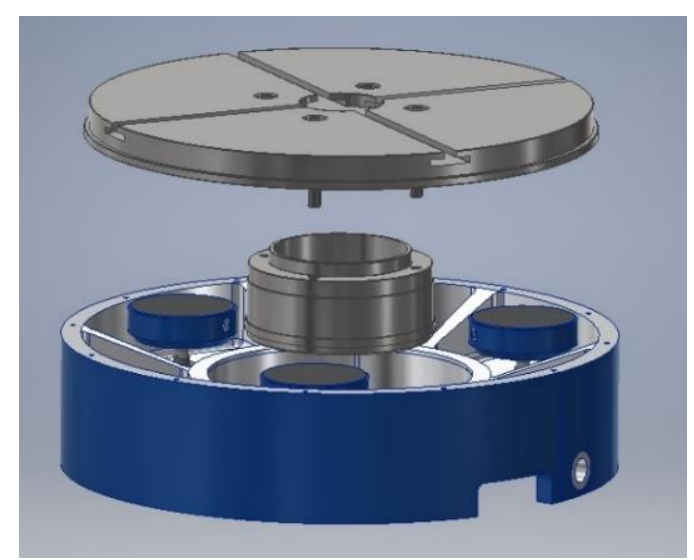

Fig. 5. Assembly of key load-bearing elements for FEM analysis

a)

b)

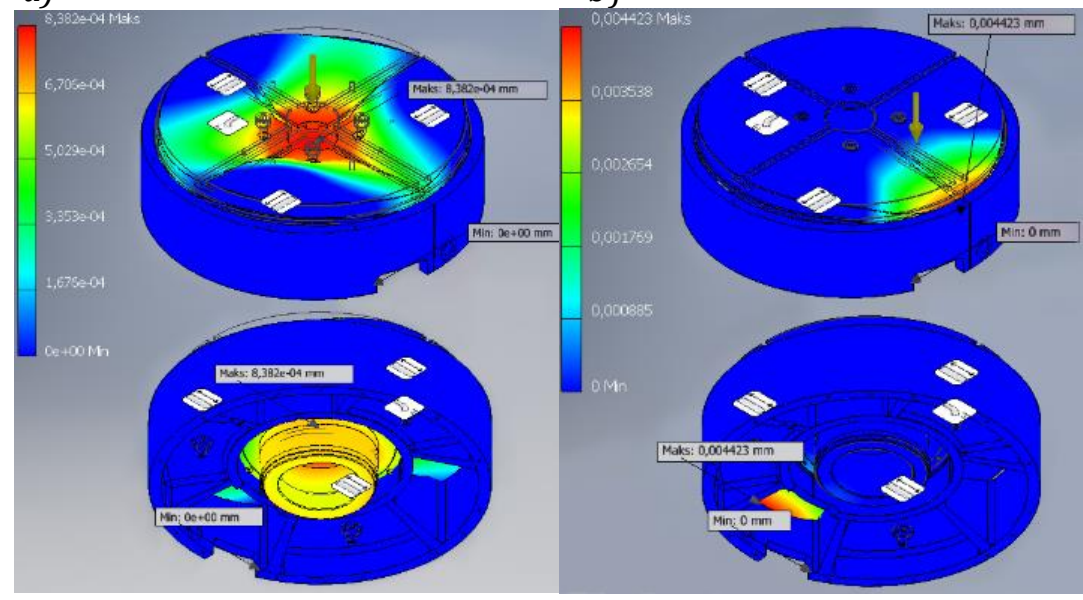

Fig. 6. Distribution of displacements at the maximum table load capacity (ø100 mm): a) displacement of the system at a load in the axis of rotation, b) displacement of the system at a load of $100 \mathrm{~mm}$ from the axis of rotation

a)

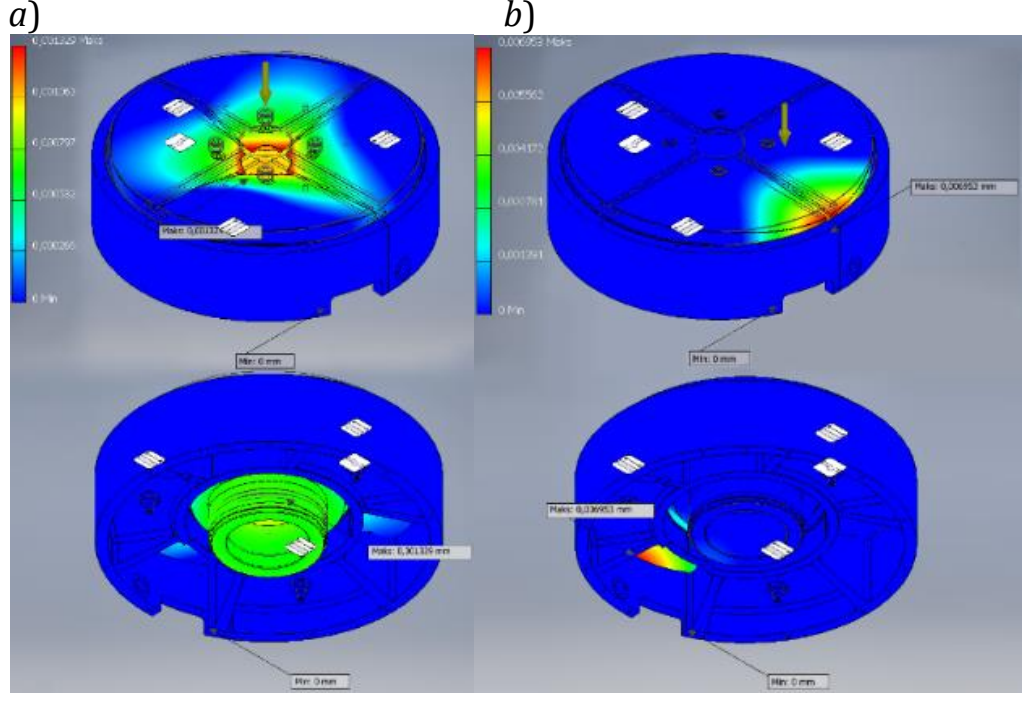

Fig. 7. Distribution of displacements at the maximum table load capacity ( $\varnothing 60 \mathrm{~mm}$ ): a) displacement of the system at a load in the axis of rotation, b) displacement of the system at a load of $100 \mathbf{~ m m}$ from the axis of rotation

Verification of the initial conditions was carried out assuming that the load on the measuring table is maximum - equal to the maximum load capacity of the axial bearings, taking into account the mass of complex elements with the table disk, i.e. pressure by $1850 \mathrm{~N}$. A serious problem is that in the case of aerostatic bearings, the table 
with the measured object rises and is supported at a height of $0.005 \mathrm{~mm}$ (with a maximum nominal load) only by the force of the airbag produced [5].

The analysis shows that the element that is most deformed is the table top. The resulting displacement (deformation) amounts of up to $0.004 \mathrm{~mm}$ (in the case of a workpiece with a diameter of $\varnothing 100 \mathrm{~mm}$ ) and $0.006 \mathrm{~mm}$ (in the case of a workpiece with a diameter of $\varnothing 60 \mathrm{~mm}$ ) for non-axial fixation of the object, are small and negligible in local construction coordinate system. However, it is recommended to evenly load the table and fix the workpiece in the table's axis of rotation. Distribution of displacements in the body (figs. 6 and 7) are not visible due to very small values compared to the displacements occurring in the table disk.

It can be stated that the designed measuring table will have a load capacity equal to the maximum load capacity of the axial bearings, minus the influence of the mass of moving elements (table disk, middle sleeve, motor rotor, etc.), amounting to approximately $188 \mathrm{~kg}$. In other words, the pre-assumed load capacity of the measuring table will not be limited by the strength of the load-bearing components.

\section{Summary}

Applying the Autodesk Inventor Professional 2018 software [4], an innovative, autonomous rotary table for coordinate measuring machines was designed. The measuring table is a portable device that can be mounted on any measuring machine. Its additional advantage is low height $(120 \mathrm{~mm})$, which only slightly limits the measuring space in $Z$ axis. Presented structure is characterized by a low weight of approximately $26 \mathrm{~kg}$. Its achievement was possible due to the optimization of dimensions and careful selection of materials for individual table construction elements. During the table design, FEM analyses were carried out many times, the results of which were the basis for changing the shape and dimensions of the structural elements. In addition, the correctness of the assumptions was confirmed and the maximum mass of the measured elements and the effect of the detail position on the accuracy of the measurements were determined. In the next steps, the table design was optimized. The final calculation results clearly confirmed the correctness of the construction assumptions. Strength of the supporting structure is consistent with the assumed load capacity of $188 \mathrm{~kg}$, and all deformations are within the range of elastic deformations (figs. 6 and 7) and are maximum $0.006 \mathrm{~mm}$.

\section{REFERENCES}

[1] Jakubiec W., Malinowski J. „Metrologia wielkości geometrycznych”. Warszawa: Wydawnictwa NaukowoTechniczne, 1993.

[2] Ratajczyk E., Woźniak A. „Współrzędnościowe systemy pomiarowe”. Warszawa: Oficyna Wydawnicza Politechniki Warszawskiej, 2016.

[3]https://www.zeiss.pl/metrologia/produkty/systemy/portalowe-maszyny-pomiarowe/prismo.html (03.2019).

[4] https://www.autodesk.pl (03.2019).

[5] https://www.newwayairbearings.com (03.2019).

[6] https://www.rls.si/en/lm13-magnetic-ring-encoder-system (03.2019).

[7] https://www.tecnotion.com (03.2019).

[8] https://automatykab2b.pl/produkty/technika-napedowa/silniki-elektryczne/8089-tecnotion-Silniki_Momentowe_QTR_FirmyTecnotion (03.2019). 